OPEN ACCESS

Edited by: Arjan Wardekker, University of Bergen, Norway

Reviewed by:

Åsa Cecilia Gerger Swartling, Stockholm Environment Institute, Sweden

Sam Grainger,

Maynooth University, Ireland

${ }^{*}$ Correspondence:

Eva Boon eva@climateadaptationservices.com

Specialty section: This article was submitted to Climate Risk Management, a section of the journal

Frontiers in Climate

Received: 08 October 2020

Accepted: 05 January 2021

Published: 18 February 2021

Citation:

Boon E, Goosen H, van Veldhoven F and Swart R (2021) Does Transformational Adaptation Require a Transformation of Climate Services? Front. Clim. 3:615291. doi: 10.3389/fclim.2021.615291

\section{Does Transformational Adaptation Require a Transformation of Climate Services?}

\author{
Eva Boon ${ }^{1 *}$, Hasse Goosen ${ }^{1}$, Felix van Veldhoven ${ }^{1}$ and Rob Swart ${ }^{2}$ \\ ${ }^{1}$ Climate Adaptation Services, Bussum, Netherlands, ${ }^{2}$ Wageningen Environmental Research, Wageningen, Netherlands
}

Cities, regions and countries are increasingly adapting to climate change. Adaptation approaches often build on disaster management activities to deal with climate extremes and make improvements to already existing systems to prepare for climate change, e.g., through water engineering or cooling existing buildings. But ideally, adaptation strategies aim also at tackling the root causes of climate risks through broader sustainable development pathways. Such transformational approaches, however, are still in their infancy. In this perspective paper we argue that there is a lack of guidance to support policy-makers to develop transformational adaptation strategies. There is a need and opportunity to develop climate services that support transformational adaptation. We explore how climate services can support transformational adaptation, drawing from literature, practical experience and illustrative examples. We identify four knowledge requirements: (1) system knowledge to identify the root causes and solutions; (2) inspirational and cross-disciplinary knowledge to develop a long-term vision; (3) a clear climate message and guiding principles to mainstream the vision; and (4) design principles that are connected to the priorities and interests of the stakeholders. We conclude that developing climate services for transformational adaptation involves a delicate process of simplifying and aggregating climate knowledge, as well as integrating it with knowledge about the physical, economic and social systems of cities and regions. This means that climate service providers need to widen their scope and skills, and collaborate with experts in the fields urban planning, landscape architecture, ecology, health, and sociology.

\footnotetext{
Keywords: climate services, transformational adaptation, long-term planning, system analysis, sustainable development
}

\section{INTRODUCTION}

Policy-makers need access to climate information to effectively plan for climate change adaptation (e.g., Fussel et al., 2006). Yet developing and delivering science-based climate knowledge that actually supports policy-makers is not straightforward. The divide between research and the valorization of knowledge products has been characterized as a "valley of death" (Markham, 2002). Climate service providers aim to bridge this gap by transforming scientific climate knowledge into "something" societal actors can use (Brooks, 2013; Buontempo et al., 2014; Brasseur and Gallardo, 2016). 
Policy-makers increasingly understand the climate change vulnerabilities of their areas and start to plan for adaptation (Biesbroek et al., 2010; Georgi et al., 2016; Aguiar et al., 2018). Adaptation practices often involve incremental changes: addressing single climate risks in targeted sectors (Araos et al., 2016; Aguiar et al., 2018). Such actions consider the short to medium term and mainly aim to conserve the achievements of the past in terms of physical infrastructures and practices. There are less examples of adaptation practices that make fundamental changes to reduce climate risks in the long term and in the context of overall development (Fedele et al., 2020).

Transformational adaptation holds the promise to avoid lockins into unsustainable development, by taking a long-term and integral perspective and addressing the root causes of climate vulnerability (Lonsdale et al., 2015; Georgi et al., 2016; Fedele et al., 2019). Yet there is little practical support for policy-makers to adopt transformational approaches, and various authors stress the need for guidance and support (e.g., see Rickards and Howden, 2012; Vermeulen et al., 2018; Chu et al., 2019). Climate services have the potential to support transformational pathways. Climate services entail "The transformation of climaterelated data-together with other relevant information-into customized products, such as [...] in relation to climate that may be of use for the society at large" (Street, 2016, p. 3). We specifically focus on services for adaptation, which "support the assessment of vulnerability in a wider perspective, and includes the design and appraisal of adaptation strategies" (Goosen et al., 2014, p. 1036).

In this perspective paper, we explore how climate services can support transformational adaptation in practice. First, we introduce our perspective to high-quality climate services (section What Kind of Climate Services Do Policy-Makers need?) and types of adaptation planning (section Adaptation Planning in Practice). Next, we introduce three Dutch examples of transformational adaptation and supportive climate services (section Three Dutch Examples of Transformational Adaptation). Finally, in section Knowledge Requirements for Climate Services That Support Transformational Adaptation we propose four knowledge requirements for climate services and provide suggestions for future climate service practice and research.

\section{WHAT KIND OF CLIMATE SERVICES DO POLICY-MAKERS NEED?}

What a policy-maker regards as "supportive knowledge" is different for specific policy-makers and their contexts (Lemos et al., 2012). Policy-makers cover specific policy domains, each having their own traditions of decision-making and knowledge use. Hence they appreciate knowledge differently. Consequently, knowledge quality is often evaluated through analysis of user perception, investigating to what extent users perceive the knowledge as salient, credible, legitimate, useful and/or usable (Cash et al., 2003; Lemos and Morehouse, 2005).

These criteria indicate the relevance of co-production for increasing knowledge quality, by generating mutual understanding of needs and possibilities; and by establishing trust (McNie, 2008; Meadow et al., 2015). The reliance on short-term user satisfaction, however, should be regarded as of limited use for the deliberate design of high-quality climate services. We argue that there are knowledge requirements typically relevant for transformational adaptation. Evidently, these general requirements should be translated to specific local actors and elaborated to suit local circumstances. Below, we explore which knowledge requirements can best support the communities producing and using climate knowledge, in order to co-produce high-quality climate services.

\section{ADAPTATION PLANNING IN PRACTICE}

There is no archetypical way of adaptation planning (Heidrich et al., 2016). It is driven by various motivations, such as recent climate disasters and political commitments (Aguiar et al., 2018). Some cities however, have started to see adaptation also as an opportunity to increase their attractiveness as livable and resilient cities (Georgi et al., 2016).

When trying to understand the practice of adaptation, an interesting perspective is to regard the rationale from which the adaptation actions come about. We distinguish three broad categories of adaptation: reactive, incremental and transformational adaptation (Georgi et al., 2016). Reactive adaptation, or coping, focuses on reducing the negative consequences during and after an extreme climate event. This type of action is common practice in natural hazard management or heatwave protocols. Incremental adaptation aims to prevent the negative consequences of climate change by protecting existing infrastructural and social systems. This is a proactive type of action. Examples are increasing the sewerage capacity or placing flood gates at buildings. Reactive and incremental adaptation actions are well-known and commonly applied. In contrast, transformational adaptation remains more elusive in practice, even if the concept is being discussed in the scientific literature. Different ideas exist on what transformational adaptation actually is (O'Brien, 2012; Feola, 2015; Lonsdale et al., 2015). Transformational adaptation, in our perspective, is about addressing the root causes of vulnerability to climate risks and about avoiding lock-ins for unsustainable development (e.g., see Fedele et al., 2019). This proactive approach goes beyond minimizing negative impacts of climate change, by the creation of added value, usually demanding more fundamental changes to the existing systems.

Examples of transformational adaptation have been much less reported than reactive and incremental adaptation (Heikkinen et al., 2019; Fedele et al., 2020). An important reason is that barriers for transformational adaptation are larger in comparison to reactive and incremental adaptation. Examples are high investments of time and resources, dealing with a plurality of stakeholders, sectors, and government levels with diverse interests and responsibilities, and divergence from the business-as-usual. Moreover, there is a lack of familiarity with transformational adaptation practices (Fedele et al., 2019). Another explanation for the limited application of 
transformational approaches may be found in the way frames and practices can be institutionalized in disciplines or organizations. For example, in policy domains where risk management is the dominant approach (e.g., in environmental, natural hazard, or water management), the range of adaptation solutions that are considered, may be largely informed by a frame that is oriented toward preventing the negative consequences of climate change, rather promoting positive outcomes (de Boer et al., 2010). Transformational adaptation may require a more positive frame to decision-making, with an integrated approach that identifies opportunities for co-benefits.

Several nuances must be added. Firstly, the distinction between the approaches is not hard. Adaptation actions and strategies can both have reactive, incremental and transformational aspects. For example, greening a neighborhood can be an incremental solution to absorb excess rainwater in a flooding hotspot. But it can also be part of a more fundamental change to improve the cities' sponge capacity and biodiversity. Secondly, we suggest there is no hierarchy between the approaches; a mix of these approaches may be needed to plan and prepare well for climate change risks. The three approaches have different advantages and disadvantages (Georgi et al., 2016). However, the underrepresentation of transformational adaptation may turn out to be costly in the long term, nullifying investments in reactive and incremental adaptation as those solutions may not be sufficient to deal with climate change.

\section{THREE DUTCH EXAMPLES OF TRANSFORMATIONAL ADAPTATION}

To illustrate how climate services can support transformational adaptation, we present examples from three local Dutch authorities. We interviewed key policy-makers in the field of adaptation from the municipality of Amersfoort and Rotterdam and the Water company of Amsterdam ${ }^{1}$. We asked them to characterize their adaptation efforts along the three adaptation approaches, and then focused on the transformational elements and the services that have supported them. Table 1 summarizes the main outcomes of the interviews. In the next paragraphs we describe some key elements that came forward.

In all authorities, the policy-makers recognized the three approaches in their practice and described a mix of reactive, incremental and transformational adaptation efforts in their areas. They recognized transformational approaches in various activities and policies, including a vision addressing the root causes of climate risks, defining long-term system goals, and starting dialogues with citizens. To support these activities, they use climate change information in a variety of forms. We observe two processes that were central to the transformational approaches and that influenced the perception of the climate

\footnotetext{
${ }^{1} \mathrm{We}$ interviewed five policy-makers that play a key role in adaptation planning. The functions of the policy-makers are: strategic advisor spatial planning (Amersfoort), advisor environmental management (Amersfoort), advisor water, subsurface, and climate (Rotterdam), advisor climate change adaptation (Rotterdam), and strategic advisor water (Amsterdam).
}

services that support transformational adaptation: stakeholder engagement and mainstreaming.

Stakeholder Engagement: The examples show that transformational adaptation requires the involvement of a wider group of stakeholders as compared to reactive and incremental adaptation. This includes both involving the wider public and engaging professionals from a diverse set of disciplines. The collaborative processes inform the formulation, concretization and implementation of transformational actions. Stakeholders with diverse knowledge are brought together to increase the understanding of the city's systems and formulate long-term goals. To concretize and implement transformational actions on the shorter term, the policymakers involve citizens and businesses. The policy-makers use easy-to-understand maps and tools to make climate risks and actions understandable.

Mainstreaming: In all examples, adaptation measures and policies are not carried out in isolation. They are mainstreamed into sectoral policies on green and the environment or they are included in integral programmes on sustainability or resilience. The policy-makers explained that climate information plays a limited role in integrating adaptation in these plans, adaptation is only one of the arguments for action. A clear and simple climate message was used to put adaptation on the agenda.

\section{KNOWLEDGE REQUIREMENTS FOR CLIMATE SERVICES THAT SUPPORT TRANSFORMATIONAL ADAPTATION}

Reflecting on scientific literature, the examples and our own experience (Goosen et al., 2014; Swart et al., 2017; Laudien et al., 2019) with supporting local and regional stakeholders in their adaptation efforts, we present four generic knowledge requirements for climate services that may support transformational adaptation processes. The requirements address four broad processes: understanding risks and solutions; vision development; mainstreaming the vision; and implementation of actions by city stakeholders. Thereafter, we discuss implications for evaluating the quality of climate services. We conclude with suggestions for future climate service practice and research.

\section{System Knowledge to Identify Root Causes and Solutions}

Addressing the root causes of climate risks is central to transformational adaptation. This requires that the mechanisms underlying the risks are well-understood. Generating knowledge on systems, their history, and dynamics has been identified as an important capacity for transformational adaptation and climate governance (Lonsdale et al., 2015; Hölscher et al., 2019). In the presented examples, especially knowledge on the natural system was used to understand the climate risks and to identify solutions. To offer relevant support for transformational adaptation, climate services should increasingly focus on how climate risks and possible solutions relate to all systems of the city. Policy-makers need a more thorough understanding of how risk mechanisms work over different scales and for 
TABLE 1 | Results of the interviews with policy-makers from three local Dutch authorities.

\begin{tabular}{ll}
\hline The municipality of Amersfoort \\
\hline $\begin{array}{l}\text { Adaptation } \\
\text { programme }\end{array}$ & $\begin{array}{l}\text { The Amersfoort adaptation strategy is part } \\
\text { of the city's Sustainable City Programme. } \\
\text { The strategy builds on a long-term regional } \\
\text { vision that regards water systems, green } \\
\text { areas and the subsurface as one interrelated } \\
\text { natural system. }\end{array}$
\end{tabular}

Transformational elements as described by the policy-makers

Supportive climate services
The municipality of Rotterdam

The Rotterdam adaptation strategy is concretized in the programme "Rotterdam Weather Wise" and integrated within the Rotterdam Resilience Strategy. The adaptation strategy aims to establish and maintain a robust water system, recognizing that the city is reaching the limits of resilience of the current systems.

The policy-makers explain that initially incremental actions were dominant, for example improving the embankments. Now, the policy-makers indicate that transformational approaches are more common. Firstly, to understand climate risks, the policy-makers began to analyze subsurface and groundwater conditions in relation to the climate risks. Secondly, the policy-makers started a dialogue with citizens on how to redevelop the city. Illustrative for the adoption of the more transformational approach, is how pluvial flooding is addressed. While first "invisible" technical measures were taken, the solutions are now designed together with citizens, sometimes even on their own initiative. This results in more broadly supported solutions that add value for the neighborhood.

To engage professionals and citizens, the policy-makers indicate that information on climate risks and solutions needs to be simplified and translated for the target groups. To reach a diversity of stakeholders, the city develops interactive maps, showing an overview of risks, priorities and opportunities. For the broader public, the narrative must be even more simple and attractive. Providing factsheets is helpful but sharing an appealing vision of the future city may be even more important.
The Water company of Amsterdam

The water company Waternet has been working for years on adaptation together with the municipality of Amsterdam. Recently, the municipality launched its long-term adaptation strategy. The strategy marks the start of an ongoing process where stakeholders of all relevant disciplines and organizations elaborate and flesh out the strategy.

The policy-maker recognizes the three adaptation approaches and emphasizes that all are needed. An example of transformational adaptation in Amsterdam is the ambition to green the city and plant more trees. Adaptation became a central theme in their vison for urban green space. However, since Amsterdam's subsurface is filled with cables and other infrastructure, this ambition cannot be realized in the short-term. Another transformational characteristic of the strategy is that it has no specified endpoint, it is rather the start of a collaborative process with stakeholders.

Waternet and the municipality used various climate services, such as localized climate variables and risk maps. The policy-maker indicated that especially for large adaptation investments, they need detailed information to substantiate expenses. Yet in cases where adaptation is only one of the arguments for action, such as greening the city, they need less detailed information. No detailed climate information was fed into the vision on urban green space. The policy-maker stresses that the most important requirement is that the information is tailored to the target audience. While risk diagrams are good instruments to start the conversation with water managers, attractive measures may help to convince citizens to green their neighborhood. different stakeholders. This includes regarding upstream and downstream areas from catchment scale to local scale and understanding groundwater, ecology, and subsurface processes. However, it also demands an understanding of the social and economic systems, for example by accounting for people's needs, behaviors, values, power relations, and economic opportunities. Next to understanding how the current systems produce risks mechanisms, policy-makers need to generate an understanding of the solutions that can reduce the vulnerability to climate risks. These solutions should have environmental, socio-economic, and cultural features. To support this process, climate services could provide practical knowledge on nature-based solutions and their local suitability. Naturally, to understand the root causes of climate risks does not only require system knowledge, one also needs a knowledge base with knowledge and information about local climate risk and vulnerability characteristics.

\section{Inspirational and Cross-Disciplinary Knowledge to Develop a Long-Term Vision}

Transformational adaptation is not something that can be done overnight and by working from a single discipline. It is about redesigning entire areas to address the root causes of climate risks, while at the same time creating added value for the area. 
This requires a long-term vision: a collective understanding of the systems that need to be changed and the development pathways that are possible and desirable. Such a vision can be developed in a collective process, engaging stakeholders from a wide range of disciplines including spatial planners, water managers, architects, health care professionals, asset managers, and citizens. To be usable for developing a collective vision, climate and system knowledge must be easily understandable and translatable to the various engaged disciplines. Moreover, a context is needed where stakeholders can pool and integrate knowledge and resources across scales and sectors (Hölscher et al., 2019). This means that knowledge should be offered in a form that facilitates interaction, inclusion, dialogue, and consensus building. This is more easily accomplished with inspirational decision-support tools that stimulate creativity (de Boer et al., 2010). In co-production with the stakeholders, the complex climate risk and system information can be translated into an appealing narrative that connects with the values and objectives of diverse stakeholders. This narrative can be further elaborated and specified in the course of the vision development process. In New York such a narrative was developed in a design competition for green infrastructure to enhance the flood resilience of the area. The outcomes pushed a long-term vision with a new visual identity and the idea to embrace water as an integral part of livability in the city (Trogrlić et al., 2018).

\section{Clear Climate Risk Message and Guiding Principles to Mainstream the Vision}

As illustrated with the examples, transformational adaptation is not a stand-alone activity, it needs to be mainstreamed into strategies, policies, and planned development that address other challenges. For adaptation planners to be able to incorporate the transformational vision in policies, strategies, and implementation plans, they must convince colleagues from other sectors to take adaptation into consideration. They need to communicate through clear messages on the climate risks and possible solutions. The examples show that climate information doesn't have a significant role to play here; there is no room for details. Rather, information that is perceived usable for mainstreaming, involves general summaries of climate trends or hotpots and guiding principles. An example of a guiding principle implemented by the city of Shanghai, is increasing the city's sponge capacity with green and permeable pavements as an ecological alternative to deal with flooding and sea level rise (C40 Cities Climate Leadership Group, 2020). Such principles are solution directions that fit the long-term vision, without exactly pinpointing what needs to be done and where. For climate services this means that underlying sophisticated and quantitative climate information needs to be summarized, narrated, and placed in a wider perspective to provide the main message on climate risks and potential solutions. This also means that the technical details, such as uncertainty information, are secondary to the general message. Incremental adaptation often requires quantification of impacts and effectiveness of solutions to underpin large engineering investments. But for transformational adaptation it is more relevant that the information can be connected to the broader environmental, social and economic challenges of the area.

\section{Design Principles That Are Connected to the Priorities and Interests of the Stakeholders}

Governments cannot implement the vision alone; they are dependent on the private sector and civil society to concretize and implement actions that redirect developments toward the long-term vision. In order to engage stakeholders to implement actions, both content and presentation method of climate knowledge need to be tailored to the various stakeholder groups. From the examples it appeared that this tailoring mostly means that stakeholders can identify with the knowledge and that it connects to their values and objectives. One way to do this is to explore potential frames that are dominant in the stakeholder groups and that drive their motivation for taking action (de Boer et al., 2010). For example, companies may be activated if they are presented with numbers of estimated losses in case of climate extremes. Citizens however, may be more likely to green their private space when they are pointed to the beauty of green and its value for health. But of course, also within these groups large differences exist.

\section{High Quality Knowledge for Adaptation}

We presented four general knowledge requirements for climate services that aim to support transformational adaptation. The requirements were identified by accounting for relevant policy-making processes and for the main principles of transformational adaptation. Evidently, the services that incorporate these knowledge requirements, have an explicit focus and intention to support the identification and implementation of transformational strategies, rather than reactive or incremental actions. This has implications for how we evaluate the quality of these and other services.

Returning to the section: what kind of climate services do policy-makers need? we argue that the quality of knowledge in services should not only be evaluated in terms of user or producer perception, but also in terms of the decisions and long-term impacts that follow from using the service. Evaluating the quality of outcomes and impacts, however, is not straightforward; it is difficult to identify how and to what extent long-term information impacts decision-making on the ground (Singh et al., 2018; Tall et al., 2018), and there are fundamental different views on approaches and metrics to evaluate adaptation efforts across actors, space and time (Doria et al., 2009; Dilling et al., 2019; Weichselgartner and Arheimer, 2019).

We therefore suggest, as a first step in evaluating the quality of outcomes and impacts, to make the climate services' underlying assumptions and intentions explicit. There is a multitude of contrasting frames on adaptation (e.g., see Dewulf, 2013), and such frames are also built-in into decision-support tools (de Boer et al., 2010). In turn these frames influence the type of approaches and actions that are promoted. Quality evaluations should make this explicit: what kind of actions 
will you identify by using this service? And what actions are consequently not considered? What are the advantages and disadvantages of using this knowledge for drafting an adaptation strategy over different scales of time? Answering these questions would enable to identify risks for maladaptation and overinvestment, when developing and using a service for a specific purpose.

\section{Way Forward}

Explicitly developing transformational adaptation plans can help to identify more holistic solutions that are sustainable in the long run. However, this demands larger investments and good sustained collaboration between policy departments and with other stakeholders. This makes transformational adaptation challenging for policy-makers and their advisors: how to reach and engage all relevant groups of stakeholders in an equal manner? How to identify and address the root causes of risks and capture opportunities? And how to establish and flesh out a vision for the future supported by citizens and businesses? This requires a delicate process of simplifying and aggregating climate knowledge and integrating it with other knowledge types to make it comprehensible and supportive to addressing multiple challenges. Climate service providers who aim to support transformational adaptation should therefore widen their scope and connect climate information to other types of expertise, such as urban planning, landscape architecture, ecology, health and sociology. We call for more research on how climate science can

\section{REFERENCES}

Aguiar, F. C., Bentz, J., Silva, J. M. N., Fonseca, A. L., Swart, R., Santos, F. D., et al. (2018). Adaptation to climate change at local level in Europe: an overview. Environ. Sci. Policy 86, 38-63. doi: 10.1016/j.envsci.2018.04.010

Araos, M., Berrang-Ford, L., Ford, J. D., Austin, S. E., Biesbroek, R., and Lesnikowski, A. (2016). Climate change adaptation planning in large cities: a systematic global assessment. Environ. Sci. Policy 66, 375-382. doi: 10.1016/j.envsci.2016.06.009

Biesbroek, G. R., Swart, R. J., Carter, T. R., Cowan, C., Henrichs, T., Mela, H., et al. (2010). Europe adapts to climate change: comparing national adaptation strategies. Glob. Environ. Change 20, 440-450. doi: $10.1016 /$ j.gloenvcha.2010.03.005

Brasseur, G. P., and Gallardo, L. (2016). Climate services: lessons learned and future prospects. Earths Future 4, 79-89. doi: 10.1002/2015EF000338

Brooks, M. S. (2013). Accelerating innovation in climate services: the 3 e's for climate service providers. Bull. Am. Meteorol. Soc. 94, 807-819. doi: 10.1175/BAMS-D-12-00087.1

Buontempo, C., Hewitt, C. D., Doblas-Reyes, F. J., and Dessai, S. (2014). Climate service development, delivery and use in Europe at monthly to inter-annual timescales. Clim. Risk Manag. 6, 1-5. doi: 10.1016/j.crm.2014.10.002

C40 Cities Climate Leadership Group (2020). Reducing Climate Change Impacts on Walking and Cycling. C40 Knowledge Hub. Available online at: https:// www.c40knowledgehub.org/s/article/Reducing-climate-change-impacts-onwalking-and-cycling (accessed July 24, 2020).

Cash, D. W., Clark, W. C., Alcock, F., Dickson, N. M., Eckley, N., Guston, D. H., et al. (2003). Knowledge systems for sustainable development. Proc. Natl. Acad. Sci. U.S.A. 100, 8086-8091. doi: 10.1073/pnas. 1231332100

Chu, E., Brown, A., Michael, K., Du, J., Lwasa, S., and Mahendra, A. (2019). "Unlocking the potential for transformative climate adaptation in cities," in Background Paper Prepared for the Global Commission on Adaptation (Washington, DC; Rotterdam). Available online at: https://wrirosscities.org/ be successfully connected to such other disciplines in different real-world situations, to support transformational adaptation.

\section{DATA AVAILABILITY STATEMENT}

All relevant data is contained within the article. The original contributions presented in the study are included in the article, further inquiries can be directed to the corresponding author/s.

\section{AUTHOR CONTRIBUTIONS}

EB led the drafting of the paper, with contributions from all co-authors. The interviews with policy-makers were conducted by EB, HG, and FvV.

\section{FUNDING}

$\mathrm{EB}, \mathrm{HG}$, and $\mathrm{FvV}$ are employed with Foundation Climate Adaptation Services. RS was employed with Wageningen Environmental Research.

\section{ACKNOWLEDGMENTS}

We thank the policy-makers from the municipality of Amersfoort and Rotterdam and from the water company of Amsterdam, for their time and for their constructive and critical inputs for this paper.

research/publication/unlocking-potential-transformative-climate-adaptationcities

de Boer, J., Wardekker, J. A., and van der Sluijs, J. P. (2010). Frame-based guide to situated decision-making on climate change. Glob. Environ. Change 20, 502-510. doi: 10.1016/j.gloenvcha.2010.03.003

Dewulf, A. (2013). Contrasting frames in policy debates on climate change adaptation. Wiley Interdiscipl. Rev. Clim. Change 4, 321-330. doi: 10.1002/wcc. 227

Dilling, L., Prakash, A., Zommers, Z., Ahmad, F., Singh, N., Wit, S. De, et al. (2019). Is adaptation success a flawed concept? Nat. Clim. Change 9, 572-574. doi: 10.1038/s41558-019-0539-0

Doria, M. de F., Boyd, E., Tompkins, E. L., and Adger, W. N. (2009). Using expert elicitation to define successful adaptation to climate change. Environ. Sci. Policy 12, 810-819. doi: 10.1016/j.envsci.2009.04.001

Fedele, G., Donatti, C. I., Harvey, C. A., Hannah, L., and Hole, D. G. (2019). Transformative adaptation to climate change for sustainable social-ecological systems. Environ. Sci. Policy 101, 116-125. doi: 10.1016/j.envsci.2019.07.001

Fedele, G., Donatti, C. I., Harvey, C. A., Hannah, L., and Hole, D. G. (2020). Limited use of transformative adaptation in response to social-ecological shifts driven by climate change. Ecol. Soc. 25:25. doi: 10.5751/ES-11381-250125

Feola, G. (2015). Societal transformation in response to global environmental change: a review of emerging concepts. Ambio 44, 376-390. doi: 10.1007/s13280-014-0582-z

Fussel, H. M., Klein, R. J. T., Füssel, H. M. H. M., Klein, R. J. T., Fussel, H. M., Klein, R. J. T., et al. (2006). Climate change vulnerability assessments: an evolution of conceptual thinking. Clim. Change 75, 301-329. doi: 10.1007/s10584-006-0329-3

Georgi, B., Isoard, S., Asquith, M., Garzillo, C., Swart, R. J., and Timmerman, J. G. (2016). Urban Adaptation to Climate Change in Europe: Transforming Cities in a Changing Climate. Copenhagen. doi: 10.2800/021466

Goosen, H., de Groot-Reichwein, M. A. M., Masselink, L., Koekoek, A., Swart, R., Bessembinder, J., et al. (2014). Climate adaptation services for the Netherlands: 
an operational approach to support spatial adaptation planning. Reg. Environ. Change 14, 1035-1048. doi: 10.1007/s10113-013-0513-8

Heidrich, O., Reckien, D., Olazabal, M., Foley, A., Salvia, M., de Gregorio Hurtado, S., et al. (2016). National climate policies across Europe and their impacts on cities strategies. J. Environ. Manage. 168, 36-45. doi: 10.1016/j.jenvman.2015.11.043

Heikkinen, M., Ylä-Anttila, T., and Juhola, S. (2019). Incremental, reformistic or transformational: what kind of change do C40 cities advocate to deal with climate change? J. Environ. Policy Plan. 21, 90-103. doi: 10.1080/1523908X.2018.1473151

Hölscher, K., Frantzeskaki, N., McPhearson, T., and Loorbach, D. (2019). Tales of transforming cities: transformative climate governance capacities in New York City, U.S. and Rotterdam, Netherlands. J. Environ. Manage. 231, 843-857. doi: 10.1016/j.jenvman.2018.10.043

Laudien, R., Boon, E., Goosen, H., and van Nieuwaal, K. (2019). The Dutch adaptation web portal: seven lessons learnt from a co-production point of view. Clim. Change 153, 509-521. doi: 10.1007/s10584-018-2179-1

Lemos, M. C., Kirchhoff, C. J., and Ramprasad, V. (2012). Narrowing the climate information usability gap. Nat. Clim. Change 2, 789-794. doi: 10.1038/NCLIMATE1614

Lemos, M. C., and Morehouse, B. J. (2005). The co-production of science and policy in integrated climate assessments. Glob. Environ. Change 15, 57-68. doi: 10.1016/j.gloenvcha.2004.09.004

Lonsdale, K., Pringle, P., and Turner, B. (2015). Transformative Adaptation: What It Is, Why It Matters and What Is Needed. Oxford. Available online at: https:// ukcip.ouce.ox.ac.uk/wp-content/PDFs/UKCIP-transformational-adaptationfinal.pdf

Markham, S. K. (2002). Moving technologies from lab to market. Res. Technol. Manage 45, 31-42. doi: 10.1080/08956308.2002.11671531

McNie, E. C. (2008). Co-producing useful climate science for policy: lessons from the RISA program (Ph. D. dissertation). University of Colorado, Boulder, CO, United States.

Meadow, A. M., Ferguson, D. B., Guido, Z., Horangic, A., Owen, G., and Wall, T. (2015). Moving toward the deliberate coproduction of climate science knowledge. Weather Clim. Soc. 7, 179-191. doi: 10.1175/WCAS-D-14-00050.1

O'Brien, K. (2012). Global environmental change II: from adaptation to deliberate transformation. Prog. Hum. Geogr. 36, 667-676. doi: $10.1177 / 0309132511425767$
Rickards, L., and Howden, S. M. (2012). Transformational adaptation: agriculture and climate change. Crop Pasture Sci. 63, 240-250. doi: 10.1071/CP11172

Singh, C., Daron, J., Bazaz, A., Ziervogel, G., Spear, D., Krishnaswamy, J., et al. (2018). The utility of weather and climate information for adaptation decisionmaking: current uses and future prospects in Africa and India. Clim. Dev. 10, 389-405. doi: 10.1080/17565529.2017.1318744

Street, R. B. (2016). Towards a leading role on climate services in Europe: a research and innovation roadmap. Clim. Serv. 1, 2-5. doi: 10.1016/j.cliser.2015.12.001

Swart, R. J., de Bruin, K., Dhenain, S., Dubois, G., Groot, A., and von der Forst, E. (2017). Developing climate information portals with users: promises and pitfalls. Clim. Serv. 6, 12-22. doi: 10.1016/j.cliser.2017.06.008

Tall, A., Coulibaly, J. Y., and Diop, M. (2018). Do climate services make a difference? A review of evaluation methodologies and practices to assess the value of climate information services for farmers: implications for Africa. Clim. Serv. 11, 1-12. doi: 10.1016/j.cliser.2018.06.001

Trogrlić, R. Š., Rijke, J., Dolman, N., and Zevenbergen, C. (2018). Rebuild by design in Hoboken: a design competition as a means for achieving flood resilience of urban areas through the implementation of green infrastructure. Water 10:553. doi: $10.3390 /$ w10050553

Vermeulen, S. J., Dinesh, D., Howden, S. M., Cramer, L., and Thornton, P. K. (2018). Transformation in practice: a review of empirical cases of transformational adaptation in agriculture under climate change. Front. Sustain. Food Syst. 2:65. doi: 10.3389/fsufs.2018.00065

Weichselgartner, J., and Arheimer, B. (2019). Evolving climate services into knowledge-action systems. Weather Clim. Soc. 11, 385-399. doi: 10.1175/WCAS-D-18-0087.1

Conflict of Interest: The authors declare that the research was conducted in the absence of any commercial or financial relationships that could be construed as a potential conflict of interest.

Copyright (c) 2021 Boon, Goosen, van Veldhoven and Swart. This is an open-access article distributed under the terms of the Creative Commons Attribution License (CC $B Y)$. The use, distribution or reproduction in other forums is permitted, provided the original author(s) and the copyright owner(s) are credited and that the original publication in this journal is cited, in accordance with accepted academic practice. No use, distribution or reproduction is permitted which does not comply with these terms. 